gendered

intelligence

understanding gender diversity

Writer, Broadcaster, Consultant and Trainer, Cambridge, UK

Ms Susan Quilliam;

susan@susanquilliam.com;

http://www.susanquilliam.com

Received 29 February 2016

Accepted 29 February 2016

Published Online First

22 March 2016

\title{
Gendered Intelligence
}

\section{Susan Quilliam}

Correspondence to

\section{WHO ARE YOU?}

Gendered Intelligence is a not-for-profit Community Interest Company. Our vision is of a world in which people are no longer constrained by narrow perceptions and expectations of gender, and where diverse gender expressions are visible and valued. Our aim is to increase understanding of gender diversity, putting the voices of young trans people at the heart of our mission.

\section{WHAT DO YOU DO?}

We work predominantly with the trans community and those who impact on trans lives, namely the broad spectrum of people who feel they are gender-variant in some way including, but not limited to, transsexual, transgender, non-binary and gender queer people. We particularly specialise in supporting young trans people aged $8-25$ years.

\section{HOW DID THE ORGANISATION COME INTO BEING?}

Dr Jay Stewart was volunteering for a trans masculine support group in the London area. Some of the younger people attending said: "We need a space too. There are things that are highly relevant to us that aren't really being addressed here". Then a colleague circulated a funding opportunity by The Wellcome Trust and we created a plan for an arts-based project that involved young trans people from across England.

What we noticed throughout this project was that young people are very intelligent when it comes to gender, in a way that the rest of society perhaps isn't. We came up with the name (and concept) of 'Gendered Intelligence'; this really cemented our project.

\section{WHO WERE YOUR FOUNDERS?}

We were founded in 2008 by Dr Jay Stewart and Dr Catherine McNamara. We now have a wide-ranging team of fulltime and freelance staff and a vibrant community of volunteers.

\section{WHY IS YOUR ORGANISATION \\ NECESSARY?}

There is poor understanding of, and support for, trans people and there are still many whose quality of life is diminished as a direct result. In addition, the trans community is thinly spread geographically and consequently trans people can feel isolated and vulnerable they suffer inequality, bullying and discrimination and do not always feel safe in everyday settings.

Young trans people in particular typically have a low sense of self-worth and experience extreme social anxiety; they often suffer low mood, panic attacks, severe depression and suicidal ideation.

Young trans people of colour experience double discrimination in the form of racism/marginalisation in majority white trans or lesbian gay bisexual transgender (LGBT) spaces and in the form of transphobia from their family or wider community. Recent research from the Race Equality Foundation found that young trans people are especially vulnerable to losing access to support networks in communities of faith and ethnicity.

\section{HOW DO YOU HELP?}

Our youth work programme is all about increasing social networks and bringing trans youth together so that they can make friends. We have three key aims as part of this work: decreasing social isolation; increasing a feeling of pride in a young person's sense of self; and helping young people to manage setbacks.

In the past year we have worked with around 300 young people through: mentoring individuals; a range of youth groups in London, Bristol and Leeds in the UK; sessions and workshops in schools and other educational settings; and our annual residential trip for young trans people. Over the years we have gathered evidence that demonstrates we make an important difference; this evidence will be published during 2016 .

We have also established a reputation as an organisation that delivers reliable, 
high-quality trans awareness training for professional development through innovative activities. Over the last year we have delivered consultation, guidance development, schemes of session plans and trans awareness training to a range of clients including: the Welsh Assembly, the National Scout and Guide Associations, Stonewall, Rugby Council, Bath and North East Somerset Council, the Football Association and the National Society for the Prevention of Cruelty to Children.

One 15-year-old trans boy said: "Gendered Intelligence has changed my life. It would not be a lie to say I had no friends before Gendered Intelligence; I had dropped out of school and was incredibly depressed. Now I have the most amazing friends who are like family to me and I feel like a part of something. I'm the happiest I have ever been".

\section{WHAT'S YOUR BIGGEST WORRY?}

These are difficult times; reports show that for society in general mental distress and suicide are on the increase. For trans people things are perhaps even more difficult because access to support and services is more limited. In particular, the economic environment is currently shrinking, and it is very difficult for us to grow and meet the demand. The solution for us is to inform and reach out to those who have an income and can afford to make donations; we will be relying on this approach more and more in the future.
WHAT'S BEEN YOUR BIGGEST TRIUMPH?

We've achieved so much that it's hard to say what our biggest triumph has been, though of special note is being part of the Women and Equalities Select Committee Trans Inquiry. At the present time, many of us feel very empowered by what we can and will achieve in the next 5 years. Now is a good time to be part of the trans community.

\section{FURTHER INFORMATION}

$\begin{array}{ll}\text { Who: } & \text { Gendered Intelligence } \\ \text { Address: } & \text { VAI, 200a Pentonville Road, London } \\ & \text { N1 9JP, UK } \\ \text { Telephone: } & +44(0) 2078325848 \\ \text { Website: } & \text { http://www.genderedintelligence.co.uk } \\ \text { Contact: } & \text { Jay Stewart (Director) } \\ \text { E-mail: } & \text { Jay.Stewart@genderedintelligence.co.uk }\end{array}$

Acknowledgements The author wishes to acknowledge the assistance of Dr Jay Stewart in the compilation of this article.

Competing interests None declared.

Provenance and peer review Commissioned; internally peer reviewed.

Editor's note This article is one in a series of occasional articles on key health organisations worldwide. The Journal would be pleased to hear from other organisations, particularly those based outside the UK, which would like to be similarly profiled.

\section{FACULTY OF SEXUAL \& REPRODUCTIVE HEALTHCARE MEMBERSHIP EXAMINATION}

The Membership Examination (MFSRH) consists of:

\section{- Part 1 Single Best Answer paper (SBA)}

London-based examination held annually in April and October. Applications for 15 April 2016 examination must be received by $\mathbf{1 0}$ January 2016 and for the $\mathbf{1 4}$ October $\mathbf{2 0 1 6}$ applications must be received by 1 July 2016. The syllabus for the Part 1 examination is on the FSRH website.

\section{Evidence Based Commentary (EBC)}

Candidates can view the released topic and candidate guidance notes on the website. There is an absolute deadline of 31 August 2016 to submit the EBC on this topic. You can submit an EBC before applying to enter the Part 1 examination.

- Part 2 Examination (CRQ, EMQ, OSCE)

Applications for the MFSRH Part 2 to be held in London June 2017 must be received by January 2017.

Further information and the Part 2 Syllabus are on the FSRH website. The qualification is subject to re-certification every 5 years. For the current MFSRH Examination Regulations, information on all components of the MFSRH examination and application forms, please visit the Faculty of Sexual and Reproductive Healthcare Website: www.ísrh.org (Examinations) or contact examsofficer@fsrh.org 